\title{
Disruption of Collagen Homeostasis Can Reverse Established Age-Related Myocardial Fibrosis
}

\author{
Nicole L. Rosin, ${ }^{*}$ Mryanda J. Sopel, ${ }^{*}$ Alec Falkenham, ${ }^{*}$ Timothy D.G. Lee, ${ }^{* \dagger \dagger}$ and Jean-Francois Légaré ${ }^{* \dagger \dagger}$
}

From the Departments of Pathology, ${ }^{*}$ Surgery, ${ }^{\dagger}$ and Microbiology and Immunology, ${ }^{\ddagger}$ Dalhousie University, Halifax, Nova Scotia, Canada

\author{
Accepted for publication \\ November 6, 2014 \\ Address correspondence to \\ Jean-Francois Légaré, M.D., \\ Department of Surgery, New \\ Halifax Infirmary, 1796 Sum- \\ mer St., Room 2269, Halifax, \\ NS B3H 3A7, Canada. E-mail: \\ jean.legare@cdha.nshealth.ca.
}

\begin{abstract}
Heart failure, the leading cause of hospitalization of elderly patients, is correlated with myocardial fibrosis (ie, deposition of excess extracellular matrix proteins such as collagen). A key regulator of collagen homeostasis is lysyl oxidase (LOX), an enzyme responsible for cross-linking collagen fibers. Our objective was to ameliorate age-related myocardial fibrosis by disrupting collagen cross-linking through inhibition of LOX. The nonreversible LOX inhibitor $\beta$-aminopropionitrile (BAPN) was administered by osmotic minipump to 38-week-old C57BL/6J male mice for 2 weeks. Sirius Red staining of myocardial cross sections revealed a reduction in fibrosis, compared with age-matched controls (5.84 $\pm 0.30 \%$ versus $10.17 \pm 1.34 \%$ ) $(P<0.05)$, to a level similar to that of young mice at 8 weeks $(4.9 \pm 1.2 \%)$. BAPN significantly reduced COL1A1 mRNA, compared with age-matched mice $(3.5 \pm 0.3$-fold versus $15.2 \pm 4.9$-fold $)(P<0.05)$, suggesting that LOX is involved in regulation of collagen synthesis. In accord, fibrotic factor mRNA expression was reduced after BAPN. There was also a novel increase in Ly6C expression by resident macrophages. By interrupting collagen cross-linking by LOX, the BAPN treatment reduced myocardial fibrosis. A novel observation is that BAPN treatment modulated the transforming growth factor- $\beta$ pathway, collagen synthesis, and the resident macrophage population. This is especially valuable in terms of potential therapeutic targeting of collagen regulation and thereby age-related myocardial fibrosis. (Am J Pathol 2015, 185: 631-642; http://dx.doi.org/10.1016/j.ajpath.2014.11.009)
\end{abstract}

Myocardial fibrosis, a common pathological feature of many cardiovascular disorders, is characterized by an overabundant deposition of extracellular matrix (ECM) molecules and/or a deficit in their degradation. ${ }^{1}$ The excess ECM protein results in loss of myocardial contractility and increased stiffness. ${ }^{1}$ The functional result of myocardial fibrosis is diastolic dysfunction and ultimately diastolic heart failure; affected patients have preserved systolic function but impaired relaxation associated with significant adverse health outcomes. ${ }^{2}$

Of particular clinical importance is the relationship of age with the development of myocardial fibrosis. The aging myocardium is associated with progressive and significant ECM deposition, which is termed age-related fibrosis. ${ }^{3}$ The degree of fibrosis, as measured by the amount of interstitial collagen, correlates with diastolic dysfunction during aging. ${ }^{4,5}$ Diastolic heart failure is reported to be the highest cause of hospitalization in elderly patients. ${ }^{6}$ The mechanisms responsible for the development of age-related myocardial fibrosis have yet to be fully characterized. Nonetheless, there is convincing evidence that the increased collagen in the myocardium of aging mice represents an imbalance involving one or more of the following: i) collagen biosynthesis by fibroblasts, ii) postsynthetic collagen processing (cross-linking), which makes collagen less prone to degradation, and iii) collagen degradation. To date, few studies have addressed the fundamental cause of such imbalance.

The mechanical strength of fibril-forming collagens is dependent on cross-links. Cross-linking can involve various processes, including enzymatically driven lysyl oxidation and nonenzymatic glycation. ${ }^{2,7}$ Nonenzymatic cross-linking and the resulting advanced glycation end products increase during aging, in part because of the accumulation over time of reactions between collagen and carbohydrates. ${ }^{8,9}$ Therapeutic reduction of glycation and therefore of advanced glycation end-product formation, as well as breaking

Supported by Canadian Institutes of Health Research grant CHR116835 (J.-F.L.) and by a BrightRed Graduate Research award from Heart and Stroke Foundation of Nova Scotia (N.L.R.).

Disclosures: None declared. 
established glycation cross-links, reduces stiffness and increases heart function in the setting of age-related fibrosis. ${ }^{10,11}$ It remains unclear, however, whether the cause of functional improvement is a reduction in cross-links or a decrease in the number of advanced glycation end products.

Enzymatic cross-linking is initiated by lysyl oxidase (LOX), which is an extracellular copper-dependent enzyme. LOX oxidizes the amino group on lysine or hydroxylysine, leading to spontaneous nonreducible bonds forming with native lysine or hydroxyproline residues on other collagen molecules. ${ }^{12}$ In addition to adding to physical strength, collagen cross-linking is believed to be responsible for making collagen more resistant to degradation by collagenases. ${ }^{12,13}$ LOX expression and activity are reported to increase with age. ${ }^{12}$ It has been postulated that an increase in collagen cross-linking by LOX directly contributes to the increase in tissue stiffness within the myocardium that occurs during aging, but to date clear evidence regarding this process is lacking. ${ }^{14}$

Transforming growth factor- $\beta$ (TGF- $\beta$ ) has been suggested as the main cytokine involved in regulating age-related myocardial fibrosis. ${ }^{2}$ This notion is supported by work demonstrating that TGF- $\beta$ is chemotactic for fibroblasts, stimulates fibroblast proliferation, and increases the synthesis of a number of ECM proteins. ${ }^{15-17}$ Mice that have diminished levels of TGF- $\beta\left(\mathrm{Tg}_{\left.\mathrm{f} b \mathrm{I}^{+/-}\right)}\right)$exhibit decreased age-related fibrosis and preserved diastolic function. ${ }^{18}$ Given the complexity of TGF- $\beta$ regulation, however, many investigators have advocated looking at downstream mediators of TGF- $\beta$, especially for identification and development of antifibrotic therapies. TGF- $\beta$ exposure increases expression of connective tissue growth factor (CTGF). ${ }^{19}$ CTGF has been shown to be involved in ECM deposition, wound repair, angiogenesis, migration, differentiation, and cell survival and/or proliferation in animal models of hypertension-related myocardial fibrosis or myocardial infarction. ${ }^{19-21}$ A similar link between CTGF expression and age-related fibrosis in the myocardium has not been addressed previously, nor the relationship between expression of other highly active profibrotic factors, such as fibroblast growth factor (FGF) and platelet-derived growth factor (PDGF), with myocardial fibrosis in the aging heart.

In the present study, we characterized the expression of several profibrotic factors early in the trajectory of aging and examined how they relate to collagen homeostasis. We also demonstrated that disruption of collagen cross-linking with LOX inhibition can have profound effects on overall collagen homeostasis, beyond structural effects on collagen, which might contribute to novel insights into the development of agerelated myocardial fibrosis and thus could lead to potential new therapies.

\section{Materials and Methods}

\section{Animals}

All work was approved by the Dalhousie University Committee on Laboratory Animals (reference number: 12-028) and was in accordance with Canadian Council on Animal Care guidelines. Male C57BL/6J mice at approximately 8, 12 , or 38 weeks of age (young to middle-aged) were purchased from the Jackson Laboratory (Bar Harbor, ME) and were housed within the Carleton Animal Care Centre at Dalhousie University. Mice were provided food and water $a d$ libitum for 1 week before experimentation.

\section{BAPN Infusion}

In a randomly selected group of 38-week-old mice, LOX activity was inhibited using the compound $\beta$-aminopropionitrile (BAPN). Mice under general anesthesia were implanted either with an Alzet osmotic minipump (Durect, Cupertino, CA) to deliver BAPN (150 mg/kg per day BAPN) (Sigma-Aldrich, St. Louis, MO) or with subcutaneous saline, as described previously. ${ }^{22}$ Animals were anesthetized using inhaled isoflurane (Baxter International, Deerfield, IL) in oxygen and were provided the analgesic buprenorphine subcutaneously. The pumps remained in place for 7 days, with fresh pumps for a further 7 days, during which time the mice were provided food and water ad libitum and were monitored for signs of morbidity.

\section{Echocardiography}

A sonographer, masked to experimental group, performed transthoracic echocardiography using a Vivid 7 ultrasound device (GE Healthcare Canada, Mississauga, ON, Canada; GE Healthcare, Little Chalfont, UK). Mice were anesthetized with isoflurane, body temperature was maintained on a heating pad, and electrocardiograms were monitored during the procedure. Two-dimensional M-mode measurements in short-axis view at the mid-papillary included left ventricular interior diameter in diastole (LVIDd) and systole (LVIDs), septal wall thickness in diastole (ISd) and systole (ISs), and left ventricular posterior wall thickness in diastole (LVPWd) and systole (LVPWs). The percentage fractional shortening (FS) was calculated, and the Teicholz method was used to calculate ejection fraction (EF). Pulsed wave tissue Doppler was used to determine the early and late mitral inflow velocities ( $E$ and $A$, respectively), and the $E / A$ ratio was calculated.

\section{Tissue Harvest}

Animals were anesthetized with isoflurane and blood was collected using cardiac puncture, followed by sacrifice via exsanguination. Hearts were harvested, weighed, and divided into three sections along the vertical axis. The base section was processed for histological examination; the other two portions were snap-frozen immediately for molecular analysis. The blood collected was allowed to coagulate at $4^{\circ} \mathrm{C}$, and then was centrifuged at $1200 \times g$ for 10 minutes for serum isolation. Serum was aliquoted and stored at $-80^{\circ} \mathrm{C}$. 
Table 1 qPCR Primers

\begin{tabular}{lll}
\hline Primer & Forward & Reverse \\
\hline CTGF & $5^{\prime}$-TCAACCTCAGACACTGGTTTCG-3' & $5^{\prime}-$ TAGAGCAGGTCTGTCTGCAAGC-3' \\
TGFB1 & $5^{\prime}$-GGTCTCCCAAGGAAAGGTAGG-3' & $5^{\prime}-$ CTCTTGAGTCCCTCGCATCC-3' \\
PDGFB & $5^{\prime}$-GCATCTGCCTGAAGTGTGTACC-3' & $5^{\prime}-$ TTAAGGACTTGACCCTGCTTCC-3' \\
FGF & $5^{\prime}$-CCAGCGGCATCACCTCGCTT-3' & $5^{\prime}-$ GGGTCGCTCTTCTCGCGGAC-3' \\
COL1A1 & $5^{\prime}$-CAACAGTCGCTTCACCTACAGC-3' & $5^{\prime}-$ GTGGAGGGAGTTTACACGAAGC-3' \\
LOX & $5^{\prime}$-TACTCCAGACTCTGTGCGCT-3' & $5^{\prime}-$ GGACTCAGATCCCACGAAGG-3' \\
18S & $5^{\prime}$-TCAACTTTCGATGGTAGTCGCCGT-3' & $5^{\prime}-$ TCCTTGGATGTGGTAGCCGTTTCT-3' \\
\hline
\end{tabular}

\section{Histological Analysis}

Formalin-fixed tissues were paraffin-embedded and serially sectioned at $5 \mu \mathrm{m}$ on a microtome. Basic myocardial histology and cellular infiltration were examined using heart cross sections stained with hematoxylin and eosin.

Immunohistochemistry for $\alpha$-smooth muscle actin (SMA) (Sigma-Aldrich) was performed on sectioned paraffinembedded tissue that was deparaffinized and heat-treated for antigen retrieval before staining. In brief, endogenous peroxidases were quenched with 3\% hydrogen peroxide, endogenous biotin was blocked (Dako biotin blocking system; Dako, Carpinteria, CA), and nonspecific staining was blocked with normal goat serum. Sections were incubated with primary antibody overnight at $4^{\circ} \mathrm{C}$, followed by host-specific biotinconjugated secondary antibody. Antibody complexes were then conjugated to avidin-biotin complex (Vectastain ABC kit; Vector Laboratories, Burlingame, CA) and developed using 3,3'-diaminobenzidine as the chromogen (Dako). Images were captured with an AxioCam HRC color camera (Carl Zeiss Microscopy, Jena, Germany).

\section{Quantification of Collagen and Fibrosis}

Collagen content was analyzed using two methods. Histological analysis using Sirius Red and fast green stains and semiquantification using a technique modified from Underwood et $\mathrm{al}^{23}$ were performed by a masked observer (N.L.R.). Image analysis software (Photoshop CS5; Adobe Systems, San Jose, CA) was used to quantify the area of tissue positive for Sirius Red relative to the total cross-sectional area, as described previously. ${ }^{19}$

Biochemical analysis using a hydroxyproline assay was used to quantify collagen content in myocardial tissue and in serum. Approximately $10 \mathrm{mg}$ of frozen tissue was homogenized in $100 \mu \mathrm{L}$ of $1 \mathrm{~mol} / \mathrm{L} \mathrm{NaCl}$ and incubated overnight at $4{ }^{\circ} \mathrm{C}$. Concentrated hydrochloric acid was added to separated supernatant and pellet and incubated at $120^{\circ} \mathrm{C}$ for 3 hours. The hydroxyproline assay was performed according to the manufacturer's protocol (Sigma-Aldrich). The assay was read on an Infinite 200 Pro plate reader (Tecan, Männedorf, Switzerland) at $560 \mathrm{~nm}$.

To quantify degradation products in the serum, equal volumes of serum and concentrated hydrochloric acid were incubated at $120^{\circ} \mathrm{C}$ for 3 hours. Activated charcoal $(5 \mathrm{mg})$ was added to each sample, the sample was centrifuged at $13,000 \times g$ for 2 minutes, and hydroxyproline assay was performed according to the manufacturer's instructions.

\section{Relative RT-qPCR}

Total RNA was isolated from snap-frozen heart sections using TRIzol reagent (Life Technologies, Burlington, ON, Canada; Carlsbad, CA) according to the manufacturer's protocol. Firststrand cDNA was synthesized from RNA using an iScript cDNA synthesis kit (Bio-Rad Laboratories, Hercules, CA). Real-time quantitative RT-PCR (RT-qPCR) was completed using iQ SYBR Green Supermix (Bio-Rad Laboratories); an iCycler iQ multicolor real-time PCR detection system thermocycler (BioRad Laboratories) was used for detection. Primers were designed against mRNA sequences of the genes of interest using PrimerBlast $^{24}$ (Table 1). Expression was normalized to the 18S rRNA gene using the Pfaffl method.

\section{Immunoblotting}

Frozen tissue was homogenized in radioimmunoprecipitation assay buffer $(150 \mathrm{mmol} / \mathrm{L} \mathrm{NaCl}, 50 \mathrm{mmol} / \mathrm{L}$ Tris- $\mathrm{HCl}$ base, $0.1 \%$ SDS, $0.1 \%$ Triton X-100, $0.5 \%$ deoxycholic acid) with the addition of protease inhibitor cocktail (Roche Diagnostics, Indianapolis, IN). Samples were denatured, and the protein was separated on a $12 \%$ SDS-PAGE gel and transferred to Immobilon polyvinylidene difluoride membrane (EMD Millipore, Billerica, MA). Membranes were blocked using 5\% nonfat milk before incubation with Smad2/3 (Cell Signaling Technology, Danvers, MA), phosphoSmad2 (Cell Signaling Technology), LOX (EMD Millipore), or $\beta$-tubulin (loading control) (Sigma-Aldrich) antibody overnight at $4{ }^{\circ} \mathrm{C}$. Blots were developed using horseradish peroxidase-conjugated goat anti-rabbit IgG (Vector Laboratories) and an Amersham ECL enhanced chemiluminescence kit (GE Healthcare).

\section{Enzyme-Linked Immunosorbent Assay}

Aliquoted serum samples were thawed and the manufacturer's protocol for CTGF enzyme-linked immunosorbent assay was performed [Uscn Life Science (USCNK), Wuhan, China]. Samples were run in duplicate at a 1:5 dilution with diluent buffer and undiluted. 
Table 2 Two-Dimensional M-Mode and Tissue Doppler Echocardiography in Young, Aged, and BAPN-Treated Aged Mice

\begin{tabular}{|c|c|c|c|c|c|c|c|c|c|}
\hline \multirow[b]{2}{*}{ Measure } & \multicolumn{3}{|c|}{8 weeks } & \multicolumn{3}{|c|}{40 weeks } & \multicolumn{3}{|c|}{40 weeks + BAPN } \\
\hline & Mean & SEM & $n$ & Mean & SEM & $n$ & Mean & SEM & $n$ \\
\hline \multicolumn{10}{|l|}{ M-mode } \\
\hline LVIDs (cm) & 0.28 & 0.01 & 5 & 0.27 & 0.02 & 5 & 0.24 & 0.03 & 4 \\
\hline $\mathrm{EF}$ & 58.76 & 2.32 & 5 & 59.33 & 1.17 & 5 & 65.44 & 4.51 & 4 \\
\hline FS (\%) & 27.48 & 1.50 & 5 & 27.65 & 0.97 & 5 & 32.85 & 2.99 & 4 \\
\hline LVPWd (cm) & 0.11 & 0.01 & 5 & 0.11 & 0.01 & 5 & $0.13^{*}$ & 0.01 & 4 \\
\hline LVPWs (cm) & 0.13 & 0.01 & 5 & 0.13 & 0.01 & 5 & 0.16 & 0.02 & 4 \\
\hline \multicolumn{10}{|l|}{ Doppler } \\
\hline$E(\mathrm{~cm} / \mathrm{sec})$ & 59.56 & 3.67 & 4 & 53.27 & 3.89 & 5 & 50.36 & 6.31 & 4 \\
\hline$A(\mathrm{~cm} / \mathrm{sec})$ & 27.25 & 2.85 & 4 & 30.55 & 1.44 & 5 & $23.34^{\dagger \dagger}$ & 1.96 & 4 \\
\hline HW/BW (mg/g) & 5.1 & 0.2 & 10 & 4.8 & 0.2 & 6 & 4.8 & 0.2 & 8 \\
\hline
\end{tabular}

${ }^{*} P<0.05$ versus 8 weeks; ${ }^{\dagger} P<0.05$ and ${ }^{\dagger \dagger} P<0.01$ versus 40 weeks.

$A$, late mitral inflow velocity; $B A P N, ~ \beta$-aminopropionitrile; $B W$, body weight; $E$, early mitral inflow velocity; $E F$, ejection fraction; $F S$, fractional shortening; $H W$, heart weight; HW/BW, hypertrophic index; IVSd, interventricular septal wall thickness in diastole; IVSs, interventricular septal wall thickness in systole; LVIDd, left ventricular interior diameter in diastole; LVIDs, left ventricular interior diameter in systole; LVPWd, left ventricular posterior wall thickness in diastole; LVPWs, left ventricular posterior wall thickness in systole.

\section{Cell Isolation and Flow Cytometry}

Hearts from mice at 8 weeks, 40 weeks, and 40 weeks + BAPN were harvested under sterile conditions and used for cell isolation in a modification of methods described previously. $^{22}$ In brief, hearts were mechanically and enzymatically digested in $1 \mathrm{mg} / \mathrm{mL}$ collagenase II solution (Cedarlane Laboratories, Burlington, ON, Canada; Burlington, NC) in Dulbecco's modified Eagle's medium (Life Technologies) at $37^{\circ} \mathrm{C}$ with agitation for 20 minutes. After two washes in Dulbecco's modified Eagle's medium containing $10 \%$ fetal bovine serum (Life Technologies), cells were strained over a $70 \mu \mathrm{m}$ cell strainer (Thermo Fisher Scientific, Waltham, MA) and resuspended in $37 \%$ isotonic Percoll medium (GE Healthcare) in Dulbecco's phosphate-buffered saline containing $5 \%$ fetal bovine serum. The $37 \%$ cell-Percoll mixture was layered over $70 \%$ isotonic Percoll medium (GE Healthcare) and was centrifuged for 25 minutes at $850 \times g$ with the brake off. The cell layer containing mononuclear cells was isolated and washed before being resuspended in fluorescenceactivated cell sorting buffer (Dulbecco's phosphate-buffered saline, $1 \%$ bovine serum albumin, and $0.1 \%$ sodium azide).

Cell surface expression of F4/80, CD11b, and Ly6C was assessed to determine the relative proportion of resident macrophages. In brief, isolated cells were incubated with fc receptor blocker (TrueStain fcX anti-mouse CD16/32; BioLegend, San Diego, CA) for 10 minutes, followed by incubation with fluorescently conjugated anti-F4/80-PerCP-Cy5.5, anti-CD11bAPC, and anti-Ly6C-PE antibodies (BioLegend) for 1 hour at $4^{\circ} \mathrm{C}$. After antibody incubations, cells were washed and fixed in $1 \%$ formalin solution for storage before analysis. Cells were analyzed with a BD FACSCalibur flow cytometer (BD Biosciences, Mississauga, ON, Canada; San Jose, CA) within 5 days of labeling. Findings were confirmed using isotype controls (rat IgG2a-PerCP-Cy5.5, rat IgG2b-APC, and rat IgG2c-PE; BioLegend). Results are expressed as mean fluorescence index of Ly6C gated on the $\mathrm{F} 4 / 80^{+}$and then the $\mathrm{CD}_{11 \mathrm{~b}}{ }^{+}$population.

\section{Statistical Analysis}

One-way analysis of variance tests were completed using Dunnett's post test to compare experimental groups with saline controls or the Bonferroni post test for comparing multiple groups. All qPCR results and direct comparisons between two groups were evaluated using a one-tailed $t$-test to compare changes in relative expression. All statistical calculations were performed using GraphPad Prism software version 4 (GraphPad Software, La Jolla, CA), and significance was determined if $P<0.05$.

\section{Results}

\section{Physiological Measurements}

A minimum of six mice were evaluated per group. The group allocations were based on age: 8,12 , and 40 weeks $( \pm 1$ week). Body weight and heart weight did not significantly change between groups (Table 2). Hypertrophy, defined in terms of the heart weight/body weight ratio, did not differ significantly between groups. 


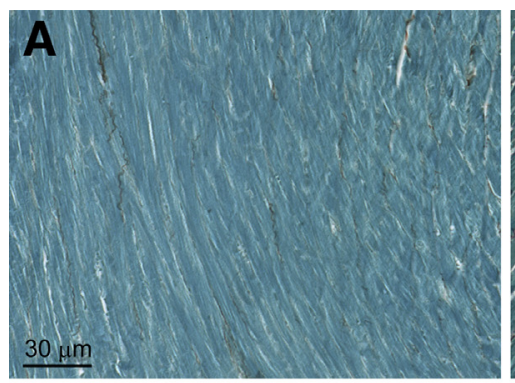

D
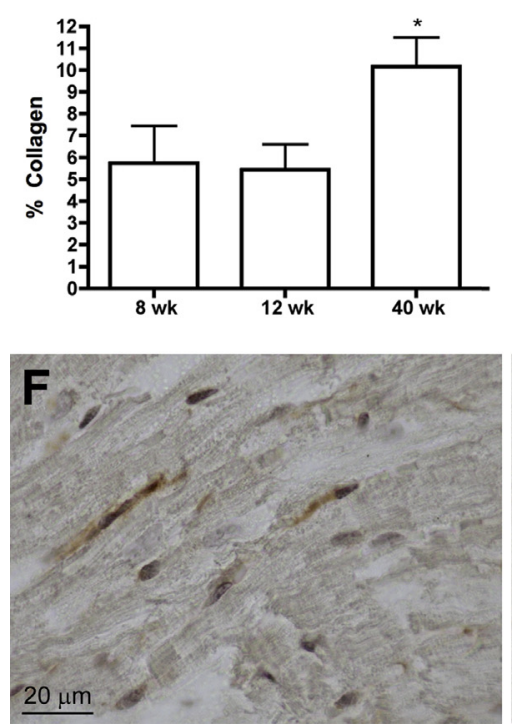

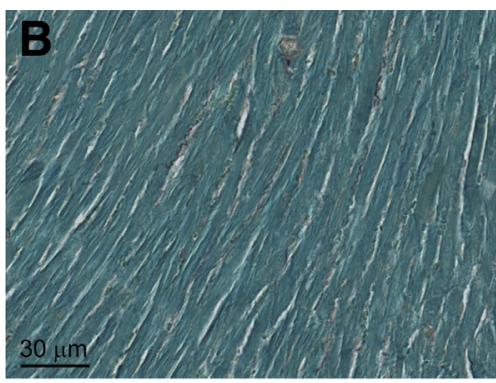

E
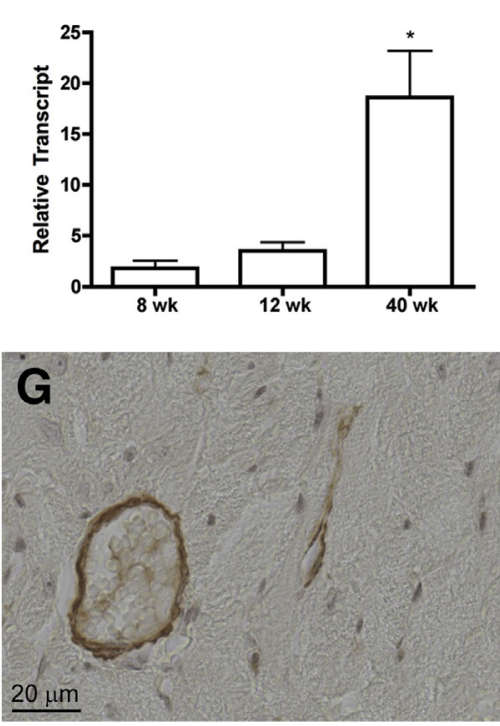

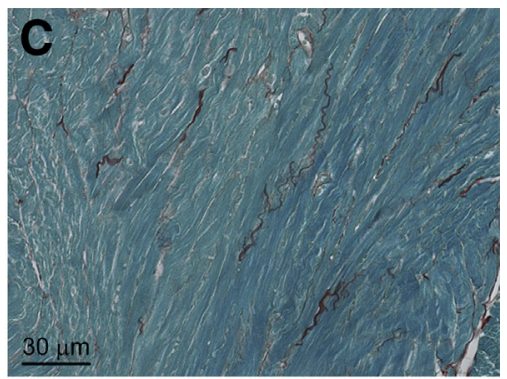

Figure 1 Development of age-related fibrosis in mouse. A-C: Fibrosis was assessed using Sirius Red staining of myocardium at 8,12 , and 40 weeks. D: The percentage of whole cross section of myocardium stained with Sirius Red was semiquantified using Adobe Photoshop CS5 image analysis software. E: Expression of COL1A1 mRNA in whole myocardium was assessed using $\mathrm{qPCR}$, normalized to the $18 \mathrm{~S}$ rRNA housekeeping gene and expressed relative to the 8-weeks group. $\mathbf{F}$ and $\mathbf{G}$ : Immunohistochemistry for SMA was performed on paraffin-fixed myocardial sections. Representative images from 40 weeks are shown (F) along with a vessel for morphological comparison (G). Data are expressed as means \pm SEM. $n=6 .{ }^{*} P<0.05$ versus 8 weeks. Original magnification: $\times 25$ $(\mathbf{A}-\mathbf{C}) ; \times 63(\mathbf{F}, \mathbf{G})$. Scale bars: $30 \mu \mathrm{m}(\mathbf{A}-\mathbf{C})$; $20 \mu \mathrm{m}(\mathbf{F}, \mathbf{G})$. qPCR, quantitative real-time PCR; SMA, $\alpha$ smooth muscle actin.
Significant Myocardial Fibrosis Develops with Age

Myocardial fibrosis was assessed using Sirius Red for collagen visualization. Interstitial and perivascular collagen increased in older mice, with darker red staining indicating the presence of denser collagen fibers in the myocardium of 40-week-old mice, compared with 8-week-old or 12-week-old mice (Figure 1, A-C). The amount of collagen was semiquantified and expressed as a percentage of total cross-sectional area affected. The myocardium of mice at 40 weeks had significantly more collagen deposition $(10.2 \pm 1.3 \%)$, compared with mice at either 8 weeks $(5.7 \pm 1.8 \%)$ or 12 weeks $(5.5 \pm 1.2 \%)(P<0.05)$ (Figure 1D).

\section{Mechanisms Involved in the Observed Collagen Increase}

Collagen type I is the most abundant ECM protein within the myocardium. ${ }^{25}$ It is actively and continually synthesized, processed (including cross-linking), and degraded. We therefore assessed collagen homeostasis within the myocardium and its relationship to aging.

\section{Collagen Synthesis}

The relative expression of collagen type I $\alpha 1$ (COL1A1) mRNA in myocardium, as assessed by qPCR, did not change significantly between 8 and 12 weeks, but was significantly elevated by 40 weeks $(15.2 \pm 4.9$-fold $)$ $(P<0.05)$ (Figure 1E). This suggests that the increase in collagen deposition observed during aging is due in part to an increase in new collagen mRNA production. Having shown that collagen increased in both mRNA and protein as early as 40 weeks of age, we stained sections of myocardium for SMA to assess the presence of myofibroblasts, a differentiated form of fibroblasts responsible for ECM production. We were able to identify myofibroblasts in the interstitium of 40-week-old mice (Figure 1F), something that was not possible in the myocardium of younger mice (Figure 1G).

\section{Collagen Cross-linking}

Hydroxyproline is present largely in collagen, making it an ideal biochemical marker for the measurement of total collagen content per microgram of tissue. ${ }^{14}$ The proportion of cross-linked collagen was assessed by comparing the amount of hydroxyproline in non- $\mathrm{NaCl}$-solubilized (cross-linked) to that in NaCl-solubilized (non-cross-linked) fractions of homogenized myocardium. There was a significant increase in total collagen in myocardium of mice at 40 weeks of age, compared with 8 weeks, which supports the Sirius Red semiquantification. Furthermore, at 40 weeks the increase in collagen appeared to be mainly in cross-linked collagen, suggesting that collagen cross-linking increased with aging (Figure 2A). 

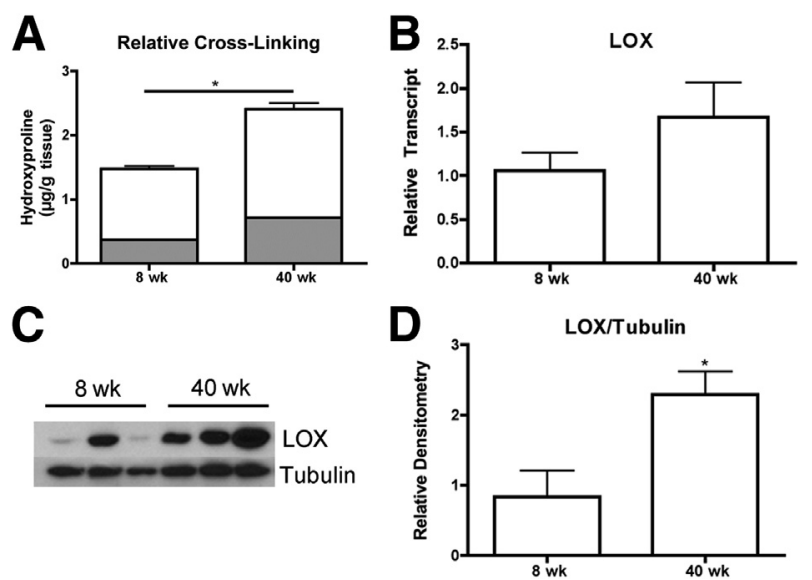

Figure 2 Collagen cross-linking. A: The amount of collagen crosslinking was determined by assessing hydroxyproline levels in NaCl-soluble (non-cross-linked; gray) and insoluble (cross-linked; white) fractions of whole myocardium. B: Expression of LOX mRNA in whole myocardium was assessed using $\mathrm{qPCR}$, normalized to the $18 \mathrm{~S}$ rRNA housekeeping gene and expressed relative to the 8-weeks group. C and D: LOX protein levels were assessed by immunoblotting (a representative Western blot is shown) (C) and semiquantified using densitometry (D). Data are expressed as means \pm SEM. $n=6$. ${ }^{*} P<0.05$ versus 8 weeks. LOX, lysyl oxidase.

LOX is the primary enzyme responsible for enzymatic cross-linking of collagen. LOX mRNA expression in the myocardium did not increase significantly in older mice, at 40 weeks, compared with younger mice at 8 weeks (Figure 2B). However, the active isotype of LOX protein in the myocardium did increase significantly at 40 weeks, compared with 8 weeks, as assessed by Western blotting ( $2.29 \pm 0.33$-fold versus $0.88 \pm 0.0 .38$-fold) $(P<0.05)$ (Figure $2, \mathrm{C}$ and $\mathrm{D})$.

\section{Age-Related Fibrosis Is Associated with a Significant Up-Regulation of Profibrotic Pathways Involving TGF- $\beta$}

Profibrotic factors are small molecules secreted within the extracellular milieu that are believed to promote the expression and deposition of ECM proteins and increase proliferation and motility of fibroblasts. ${ }^{19}$ One such growth factor, TGF- $\beta$, is recognized as a key fibrotic signaling molecule in many fibrotic disorders. ${ }^{1}$ We therefore investigated the involvement of the TGF- $\beta$ signaling pathway in age-related myocardial fibrosis. By 40 weeks of age, TGF- $\beta$ mRNA expression within the mouse myocardium was significantly elevated $(2.9 \pm 1.0$-fold), compared with 8 or 12 weeks of age $(P<0.05)$ (Figure $3 \mathrm{~A})$. The fibrotic effects of TGF- $\beta$ are in part mediated by TGF- $\beta$ receptor activation and the intracellular SMAD signaling pathway. ${ }^{17}$ SMAD2/3 protein expression and SMAD2 phosphorylation were determined by immunoblotting. Total SMAD2/3 protein expression increased significantly with aging. In conjunction, the relative amount of p-SMAD2 also significantly increased at 40 weeks, compared with 8 weeks $(P<0.01)$, although the ratio of p-SMAD2 to SMAD2/3 did not change (Figure 3, B and C).
We also assessed the production of CTGF, a downstream fibrotic mediator of TGF- $\beta$. CTGF mRNA expression within the myocardium was significantly increased at 40 weeks $(7.0 \pm 2.8$-fold), compared with 8 weeks or 12 weeks $(P<0.05)$ (Figure 3D). The concentration of CTGF protein in the serum, which has previously been suggested as a biomarker for heart failure ${ }^{26}$ and which thus may be a useful marker of an increased profibrotic state, was also significantly increased by 40 weeks $(5.52 \pm 0.45 \mathrm{ng} / \mathrm{mL})$, compared with 8 weeks $(0.46 \pm 0.40 \mathrm{ng} / \mathrm{mL})$, with no significant change at 12 weeks $(P<0.01)$ (Figure 3E). Taken together, these findings strongly support the notion that TGF- $\beta$ signaling is significantly up-regulated in aging myocardium.

The expression of PDGF and FGF, two other profibrotic factors that increase fibroblast proliferation and collagen deposition, ${ }^{27,28}$ were also assessed within the myocardium. PDGF and FGF mRNA levels were significantly up-regulated at 40 weeks $(7.0 \pm 2.0$-fold and $2.5 \pm 0.5$-fold), compared with younger mice $(P<0.05)$ (Figure $3, \mathrm{~F}$ and $\mathrm{G}$ ).

Taken together, these findings show that, as early as 40 weeks, significant changes can be identified within the myocardium that are consistent with development of agerelated fibrosis. Our findings suggest that an imbalance between ECM deposition and degradation favoring increased accumulation of collagen was already established at this age and contributed to age-related fibrosis. Furthermore, these changes in the ECM were associated with significant increases in profibrotic signaling (TGF- $\beta$, CTGF, PDGF, and FGF), suggesting that these molecules are likely key regulators of the process through a mechanism or mechanisms that have yet to be defined.

\section{Age-Related Fibrosis Is Reversible by Disrupting Collagen Homeostasis}

To better understand the links between collagen homeostasis and profibrotic signaling, we sought to disrupt one of the final stages of the post-transcriptional regulation of collagen synthesis, namely, the cross-linking of lysine (and/or hydroxylysine) groups initiated by LOX. ${ }^{29}$ The LOX inhibitor BAPN was administered to 38-week-old mice for 2 weeks, which allowed these mice to be compared with untreated 40-week-old control mice. Analysis of Sirius Red-stained cross sections showed that collagen deposition was significantly reduced in BAPN-exposed 40-week-old mice $(5.84 \pm 0.30 \%$ versus $10.17 \pm 1.34 \%)(P<0.05)$ (Figure 4, A-C). In fact, collagen deposition in BAPNtreated mice at 40 weeks did not differ significantly from that observed in the myocardium of young mice at 8 weeks $(5.74 \pm 1.70 \%)$ (Figure 4C). In support of the mechanistic effects of BAPN on cross-linking, there were significant reductions in the amount of cross-linked collagen $(1.33 \pm 0.09,40$ weeks + BAPN; $1.69 \pm 0.10,40$ weeks $)$ $(P<0.05)$ and total collagen $(1.68 \pm 0.09,40$ weeks + BAPN; $2.41 \pm 0.21$, 40 weeks $)(P<0.05)$ within 

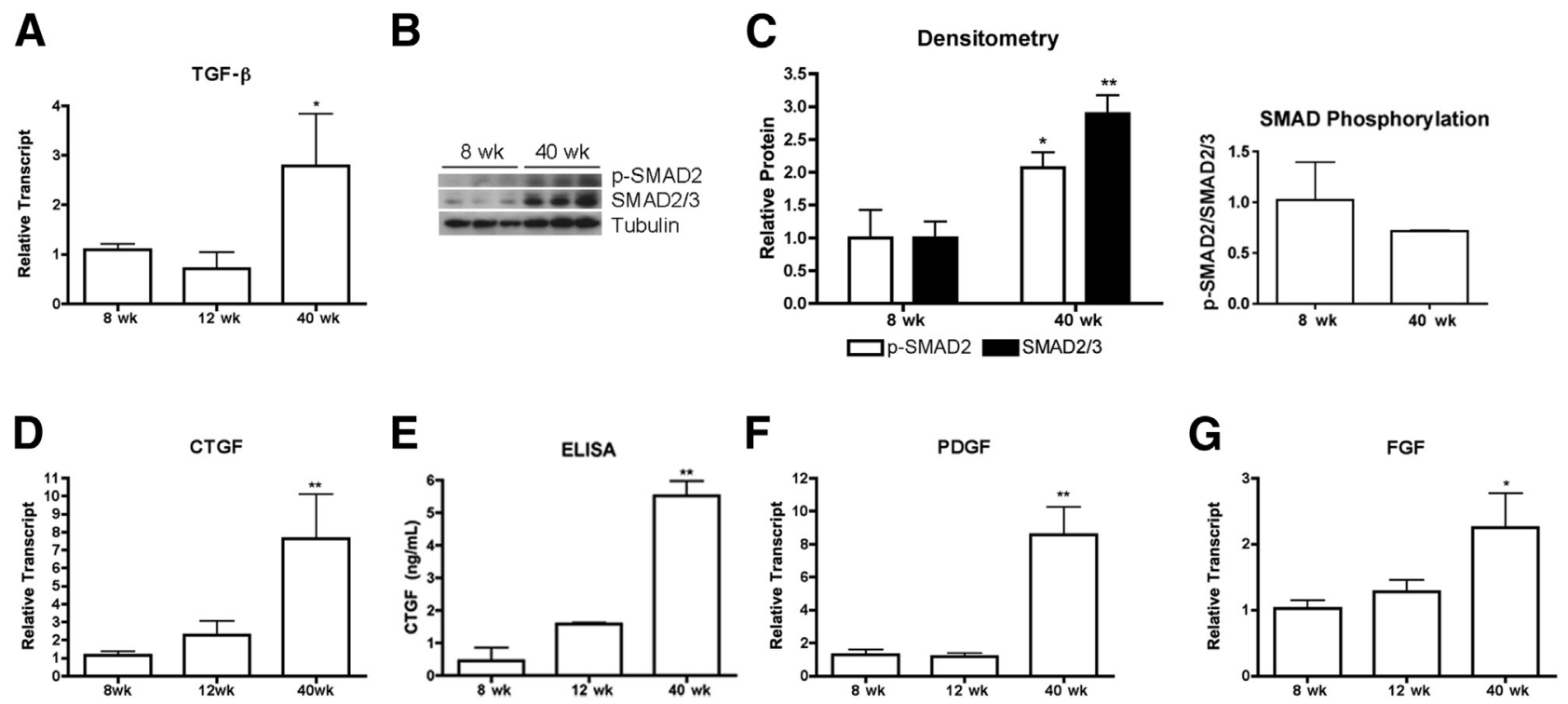

Figure 3 Fibrotic growth factors and aging. A: TGF- $\beta$ mRNA expression in whole myocardium was assessed using qPCR, normalized to the 18S rRNA housekeeping gene, and expressed relative to the 8-weeks group. B and C: Downstream signaling of TGF- $\beta$ was determined by assessing SMAD2 phosphorylation with immunoblotting. A representative blot is shown with $\beta$-tubulin as a loading control, total SMAD2/3, and p-SMAD2 levels (B), along with semiquantification using densitometry (C). D: CTGF mRNA expression in the myocardium was assessed using qPCR. E: CTGF protein levels were assessed in serum using ELISA. $\mathbf{F}$ and G: PDGF (F) and FGF (G) mRNA expression in the myocardium was determined using qPCR. Data are expressed as means \pm SEM. $n=3$ (E); $n=6(\mathbf{A}-\mathbf{D}, \mathbf{F}, \mathbf{G}) .{ }^{*} P<0.05,{ }^{*} P<0.01$ versus 8 weeks. ELISA, enzyme-linked immunosorbent assay.

the myocardium after exposure to BAPN, compared with the control at 40 weeks (Figure 4D).

\section{LOX Inhibition Also Affects Collagen Homeostasis Beyond Collagen Cross-Linking}

BAPN exposure resulted in a significant reduction in COL1A1 mRNA expression, compared with untreated control mice at 40 weeks ( $3.50 \pm 0.29$ versus $15.22 \pm 4.90$-fold $)(P<0.05)$. The expression of COL1A1 in BAPN-treated myocardium was not significantly different from that in 8-week-old mice (Figure 4E). Similarly, after BAPN exposure the TGF- $\beta$, CTGF, PDGF, and FGF expression levels were all significantly reduced, compared with myocardium of untreated controls at 40 weeks $(1.37 \pm 0.19$, TGF- $\beta ; 0.83 \pm 0.22$, CTGF; $1.40 \pm 0.21$, PDGF; and $1.19 \pm 0.12$, PDGF) $(P<0.05)$ and did not differ significantly from the levels observed in young myocardium at 8 weeks (Figure $4 \mathrm{~F}$ ). Supporting these findings, serum CTGF concentrations were also significantly reduced after BAPN exposure $(2.65 \pm 0.08$ versus $5.52 \pm 0.45 \mathrm{ng} / \mathrm{mL})(P<0.01)$ (Figure $4 \mathrm{G})$. These results suggest that LOX inhibition with BAPN not only affects cross-linking of collagen, but also affects overall collagen production and profibrotic signaling. In support of this observation, BAPN exposure also reduced LOX mRNA expression within the myocardium, compared with 40-week-old mice (Figure 4H), and was associated with a significant reduction in the active isoform of LOX protein within the myocardium (2.29 \pm 0.33 -fold, 40 weeks; $1.33 \pm 0.22$-fold, 40 weeks + BAPN) $(P<0.05)$ (Figure 4 ,
I and J). In summary, LOX inhibition with BAPN was able to reverse age-related fibrosis. However, the mechanism for this effect appears to be beyond the merely structural effects of reducing collagen cross-linking, and suggests a complex relationship between ECM proteins and the molecular signals involved in ECM regulation.

\section{Functional Effects of BAPN Exposure}

Echocardiography was used to assess cardiac function at 8 weeks and at 40 weeks, both without BAPN and after 2 weeks of BAPN exposure (Table 2). We compared the $E$ and $A$ (early and late mitral inflow velocities) or the $E / A$ ratio measured using pulsed wave Doppler, which is a standard method for assessing diastolic function. ${ }^{30}$ The absolute value of $A$ (Table 2) was significantly decreased after BAPN treatment, as was the LVPWd (Table 2). However, the E/A ratio was significantly reduced at 40 weeks, compared with 8 weeks, suggesting alterations in diastolic function in aging mice $(P<0.05)$ (Figure 5A). The 2 -week exposure to BAPN appeared to restore the $E / A$ ratios to normal, with no significant difference between BAPN-treated mice at 40 weeks and young mice at 8 weeks mice (Figure 5A). This suggests that BAPN treatment for only 2 weeks was sufficient not only to reverse some myocardial fibrosis but also to allow some recovery of diastolic function. There were no significant changes in M-mode measurements of cardiac chamber measurements (Table 2), except for an increase in LVPWd with exposure to BAPN, compared with 8-week-old mice (Figure 5B). The maintenance of ejection fraction (EF) and 

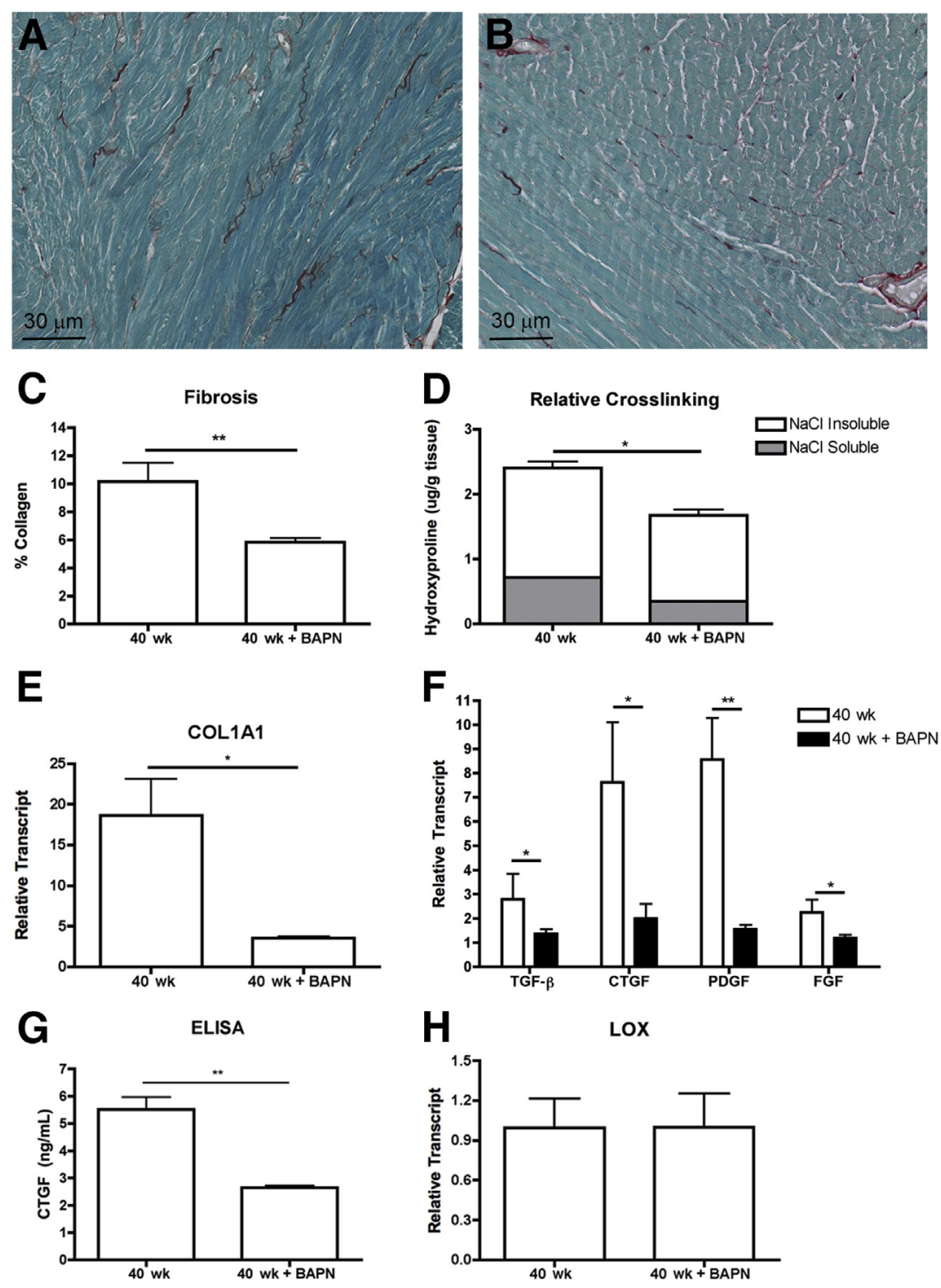

H
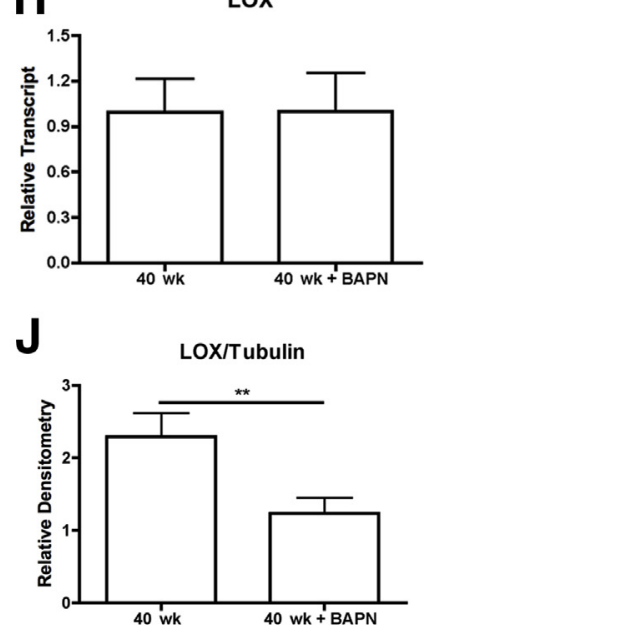

Figure 4 Lysyl oxidase (LOX) inhibition and collagen processing. $\mathbf{A}$ and $\mathbf{B}$ : LOX inhibitor $\beta$-aminopropionitrile (BAPN) was administered by osmotic minipump for 2 weeks before sacrifice of mice at 40 weeks. Fibrosis was assessed in the myocardium using Sirius Red staining of formalin-fixed, paraffin-embedded cross sections. Images are representative of myocardium at 40 weeks without (A) and with (B) 2 weeks of BAPN exposure. C: The percentage of whole cross section of myocardium stained with Sirius Red was semiquantified using Adobe Photoshop CS5 image analysis software. D: The amount of collagen cross-linking was determined by assessing hydroxyproline levels in $\mathrm{NaCl}$-soluble and $\mathrm{NaCl}-$ insoluble fractions of whole myocardium sections. $\mathbf{E}$ and $F$ : The mRNA expression of COL1A1 (E) and of TGF- $\beta$, CTGF, PDGF, and FGF (F) in the myocardium was assessed by qPCR, normalized to the 18S rRNA housekeeping gene and expressed relative to the 8-weeks group. G: CTGF protein levels were assessed in serum using ELISA. H: LOX mRNA expression was assessed using qPCR. I and J: LOX protein levels were assessed by immunoblotting (a representative Western blot is shown) (I) and semiquantified using densitometry (J). Data are expressed as means \pm SEM. $n=6 .{ }^{*} P<0.05$, ${ }^{* *} P<0.01$ versus 40 weeks. Original magnification, $\times 25$. Scale bars $=30 \mu \mathrm{m}$ fractional shortening (FS) suggests that systolic function was maintained at 40 weeks and was not affected by 2 weeks of BAPN exposure (Table 2).

\section{Cellular Contribution}

Interrupting collagen cross-linking and thereby altering the extracellular environment may affect the function of a number of cell types. Cardiomyocytes, fibroblasts, vascular smooth muscle cells, and endothelial cells make up the majority of cells within the myocardial tissue. ${ }^{31}$ However, a population of resident macrophages may play a key effector role in the myocardium. ${ }^{32}$ These macrophages have a basal alternatively activated phenotype, are $\mathrm{F} 4 / 80^{+} \mathrm{CD} 11 \mathrm{~b}^{+} \mathrm{Ly} 6 \mathrm{C}^{\mathrm{low}}$, and are thought to act in an anti-inflammatory manner to modulate the myocardial environment in response to fibrotic stimuli. ${ }^{33,34}$

The morphology of the myocardium did not appear to change, nor were there observable changes in mononuclear cells within the myocardium between 8 weeks and 40 weeks or 40 weeks + BAPN (Figure 6, A-C). The contribution of resident macrophages to ECM accumulation in aging myocardium has not yet been addressed in the literature. 
A

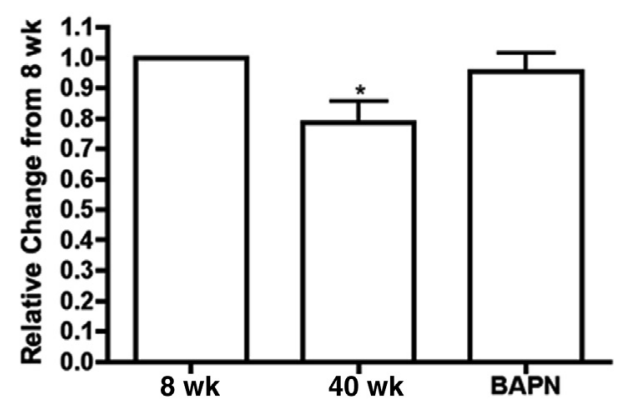

B

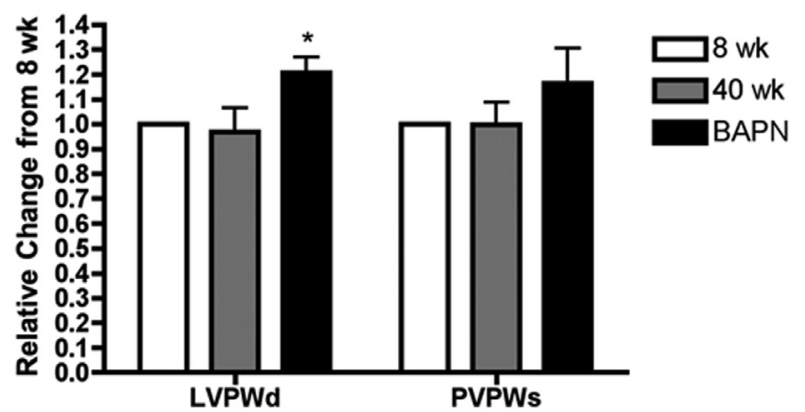

Figure 5 Functional effects of lysyl oxidase (LOX) inhibition. A: Tissue Doppler and two-dimensional M-mode echocardiography were used to assess cardiac function in mice at 8 weeks, 40 weeks, and 40 weeks + BAPN. Doppler measurements included early and late mitral inflow velocities, and the change in the $E / A$ ratio relative to 8 weeks was calculated. B: Relative change in wall thickness from 8 weeks. Data are expressed as means \pm SEM. $n=5$. ${ }^{*} P<0.05$ versus 8 weeks. $E$, early mitral inflow velocity; $A$, late mitral inflow velocity.

The Ly6C mean fluorescence index (MFI) in the resident macrophage $\left(\mathrm{F} 4 / 80^{+} \mathrm{CD} 11 \mathrm{~b}^{+}\right)$population isolated from the myocardium did not significantly increase in 40-week-old mice, compared with at 8 weeks (Figure 6, D, E, and G). However, the Ly6C MFI was significantly increased after exposure to BAPN (Figure 6, F and G), suggesting a shift toward a classically activated phenotype and consequently away from the alternatively activated phenotype within the myocardium. Taking these findings together, it appears that there may be differences in the proportions of different resident macrophage populations present during aging and BAPN exposure; however, this question was beyond the scope of the present study and would require further investigation.

\section{Discussion}

Normal aging is associated with important changes in the myocardium, most notably the development of age-related myocardial fibrosis. Most previous studies of age-related myocardial fibrosis have described changes between 8 to 12 weeks and 56 to 64 weeks in mice. ${ }^{35,36}$ With the present study, we have demonstrated that a significant increase in interstitial and perivascular collagen can be observed as early as 40 weeks of age in mice. The age of our mice is equivalent to a human age of approximately 40 years ${ }^{37}$ suggesting that age-related changes seen in the myocardium begin early in the development of age-related myocardial fibrosis. Moreover, very few studies thus far have focused on changes that occur solely as a result of aging, instead comparing differences between fibrosis models (eg, transgenic expression of angiotensin II in cardiomyocytes, ${ }^{38}$ senescence-accelerated mice, ${ }^{4}$ or ischemia reperfusion ${ }^{39}$ ) or comparing antihypertensive regimes in the setting of advanced age. ${ }^{40}$ Although these studies have yielded important information about responsiveness at different ages, key gaps remain in our knowledge of baseline alterations in fibrotic signaling within the myocardium during aging and, more particularly, their contribution to the development of myocardial fibrosis.

The progressive reduction in cardiac diastolic function during aging is well established, as both tissue Doppler and transmitral flow measurements echocardiographic assessments indicate. ${ }^{30,41}$ This age-related change was corroborated in the present study. Functional effects of increased collagen were evident in 40-week-old mice, which is in accordance with a known correlation between increasing collagen content in the myocardium and decreased diastolic function with advancing age. ${ }^{10,42}$ Our intent was to focus on the underlying mechanisms that regulate collagen homeostasis and their contribution to the increase in myocardial fibrosis seen in aging.

The well-described growth factor TGF- $\beta$ is a pleiotropic protein, and one of its roles is promotion of fibrosis by increasing fibroblast proliferation and production of ECM proteins, including collagen. ${ }^{2}$ TGF- $\beta$ has been reported to increase in the myocardium during aging, although why this occurs remains poorly understood. ${ }^{43,44}$ We observed an increase in TGF- $\beta$ signaling in the myocardium as early as 40 weeks. In addition to this increase in TGF- $\beta$, we also report here for the first time an age-related increase in the production of the downstream mediator CTGF. This increased TGF- $\beta$ signaling occurred concurrently with a significant increase in myocardial collagen accumulation, suggesting that the increase in TGF- $\beta$ may be contributing to increased deposition of ECM proteins during aging. This finding complements the observed increase in the number of myofibroblasts, which are believed to be the major effector cell type responsible for ECM production and an important source of profibrotic cytokines. However, despite providing further evidence that increased TGF- $\beta$ signaling is likely involved in age-related fibrosis, we have not elucidated the exact underlying mechanism, nor circumstances influencing it.

The present results also suggest that the increase in collagen within the myocardium is due in part to an increase in cross-linked collagen. At first glance, this increase in cross-linking did not appear to be caused by an increase in mRNA for LOX, an enzyme responsible for cross-linking, but there was an increase in active LOX protein in 40-weekold mice. Such an increase has been described in aging 

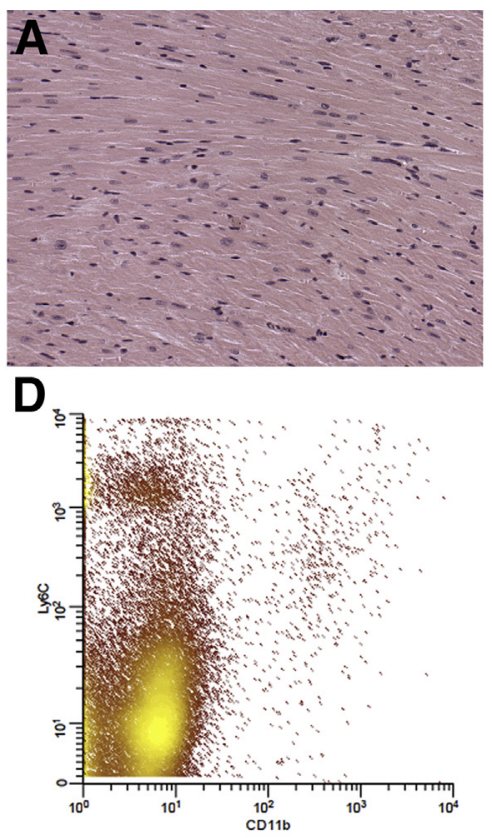

G

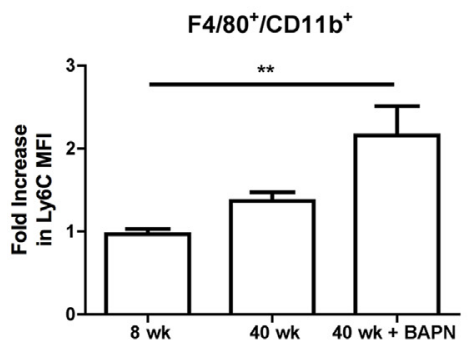

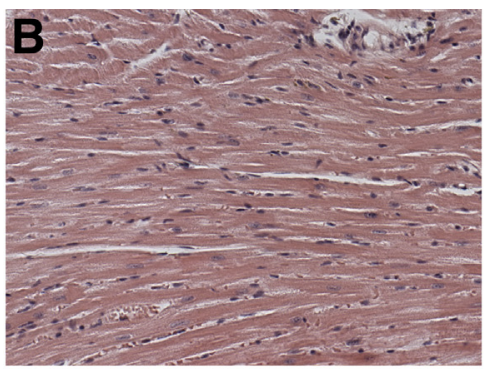

$\mathbf{E}$

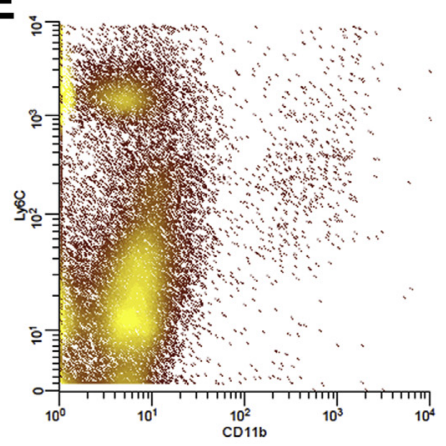

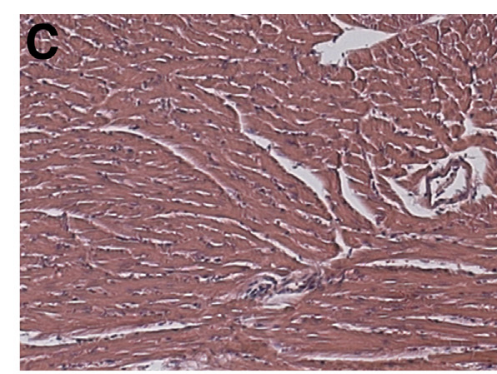

$\mathbf{F}$

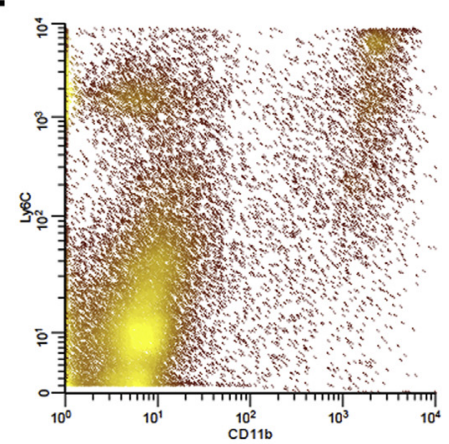

Figure 6 Cellular components. Effector cell presence was assessed by histology and flow cytometry. Hematoxylin and eosin staining revealed no qualitative changes in cellular morphology of myocardial cross sections at 8 weeks (A), 40 weeks (B), or 40 weeks with BAPN (C). Representative flow cytometry dot plots of Ly6C versus CD11b (gated on the $\mathrm{F} 4 / 80^{+}$population) of cells isolated from the myocardium at 8 weeks (D), 40 weeks (E), and 40 weeks + BAPN (F). The relative MFI of Ly6C was calculated relative to that at 8 weeks $(\mathbf{G})$. Data in $\mathbf{G}$ are expressed as means \pm SEM. $n=3$. ${ }^{* *} P<0.01$ versus 8 weeks. MFI, mean fluorescence index.

myocardium. ${ }^{12}$ In turn, collagen cross-linking is understood to have a significant effect on turnover, by inhibiting collagen breakdown. ${ }^{45}$ Our present results suggest that aging is associated with increased LOX protein and TGF- $\beta$ signaling, overall favoring a decrease in degradation and an increase in ECM accumulation and thus supporting a profibrotic environment.

Given the apparent importance of collagen cross-linking in age-related fibrosis, we sought to alter this process by using BAPN to inhibit LOX. BAPN functions by covalently and irreversibly binding to LOX, thereby inhibiting its function. ${ }^{46}$ The result of this inhibition is a decrease in collagen cross-linking, which reduces the stability of newly deposited collagen and ultimately results in greater breakdown of collagen and the release of breakdown products into the extracellular environment. As predicted from its pharmacological properties, BAPN exposure significantly reduced the amount of cross-linked collagen within the myocardium and thereby affected collagen homeostasis. However, in contrast to previous report, ${ }^{47}$ BAPN exposure did not result in an increase in soluble collagen. We sampled only once, after 2 weeks of BAPN treatment, so we may have missed the window during which soluble collagen is present. What is unique here is that administration of BAPN at a constant rate using an osmotic pump significantly decreased the total amount of myocardial collagen and increased the $E / A$ ratio after only 2 weeks to levels seen in much younger mice.

BAPN appeared to affect not only the ECM, but also the cellular elements within the myocardium. Resident macrophages within the aged myocardium after BAPN exposure (40 weeks + BAPN) had increased surface expression of Ly6C, compared with 8 weeks, whereas there was no change due to age alone (40 weeks). This suggests a shift from the basal alternatively activated (Ly6C $\mathrm{C}^{\text {low }}$ ) to the more classically activated (Ly6C $\mathrm{C}^{\text {high }}$ ) phenotype. Determining the origin of this tissue macrophage population was beyond the scope of the present study, and it remains unclear whether these cells are differentiating from the resident population or whether classically activated macrophages are being recruited. Nonetheless, the increase in Ly6C expression after BAPN exposure may be indicative of an adaptive response to the alteration of the extracellular environment brought about by disruption of collagen homeostasis.

Other potential mechanisms of regulation between cross-linking and TGF- $\beta$ signaling have been explored previously. LOX can directly inhibit TGF- $\beta$ activity. ${ }^{48}$ It also seems that LOX regulates protein synthesis of 
HIF-1 $\alpha$ enzymatically through the mitogen-activated kinase pathway (PI3K) and through reactive species production (hydrogen peroxide). ${ }^{49}$ Increased HIF- $1 \alpha$ in turn increases expression of TGF- $\beta$, thereby increasing fibroblast proliferation and collagen expression. ${ }^{50}$ At the same time, TGF- $\beta$ increases LOX expression and activity. ${ }^{51}$ This in turn acts as a feedback mechanism by reducing TGF- $\beta$ expression and cross-linking TGF- $\beta$-induced newly synthesized collagen.

In previous studies, BAPN has been administered in combination with either aortic banding or angiotensin II exposure as a model of aortic aneurysm; increased pressure in combination with reduced structural integrity of the elastic lamina results in failure of the vessel wall. ${ }^{52,53}$ Because of the copper dependency of LOX, its activity can also be inhibited with copper chelation or a copper-deficient diet. Either of these methods can, over extended periods of time, result in severe adverse effects, including vessel and ventricle rupture due to lack of structural collagen and elastin. ${ }^{54}$ In the present study, we observed no obvious adverse effects; neither ventricular diameter nor heart geometry changed, and wall thickness was not adversely affected after BAPN exposure. Our present findings do not suggest that BAPN can become a safe treatment for fibrosis, but do suggest that disrupting LOX activity and/or collagen cross-linking may provide some beneficial effects, through mechanisms that have yet to be explored in detail.

Here, we have provided novel evidence that modulating collagen homeostasis could hold potential as a future therapeutic route to reducing the burden of myocardial fibrosis in heart failure. Our findings also suggest that fibrosis may be reversible, in that the myocardium of older mice exposed to BAPN resembled that of young mice. Finally, our findings show for the first time that LOX inhibition can also result in a significant down-regulation of profibrotic signaling. This observation suggests that LOX inhibition, and therefore LOX itself, may have complex effects on the regulation of collagen, beyond direct involvement in collagen crosslinking. The mechanisms underlying our observations remain unclear, but we suggest that collagen or the products of its breakdown could be key in regulating collagen homeostasis-although the as yet unidentified signaling or feedback mechanisms need to be further explored.

\section{Acknowledgments}

We thank Tanya Myers for technical expertise and Dr. Michael Vician for sonography.

\section{References}

1. Berk BC, Fujiwara K, Lehoux S: ECM remodeling in hypertensive heart disease. J Clin Invest 2007, 117:568-575

2. Biernacka A, Frangogiannis NG: Aging and cardiac fibrosis. Aging Dis $2011,2: 158-173$
3. Chen W, Frangogiannis NG: The role of inflammatory and fibrogenic pathways in heart failure associated with aging. Heart Fail Rev 2010, $15: 415-422$

4. Reed AL, Tanaka A, Sorescu D, Liu H, Jeong EM, Sturdy M, Walp ER, Dudley SC Jr, Sutliff RL: Diastolic dysfunction is associated with cardiac fibrosis in the senescence-accelerated mouse. Am J Physiol Heart Circ Physiol 2011, 301:H824-H831

5. Besse S, Delcayre C, Chevalier B, Hardouin S, Heymes C, Bourgeois F, Moalic JM, Swynghedauw B: Is the senescent heart overloaded and already failing? Cardiovasc Drugs Ther 1994, 8:581-587

6. Barasch E, Gottdiener JS, Aurigemma G, Kitzman DW, Han J, Kop WJ, Tracy RP: Association between elevated fibrosis markers and heart failure in the elderly: the Cardiovascular Health Study [Erratum appeared in Circ Heart Fail 2009, 2(6):e4]. Circ Heart Fail 2009, 2:303-310

7. Ricard-Blum S: The collagen family. Cold Spring Harb Perspect Biol 2011, 3:a004978

8. Baynes JW: The role of AGEs in aging: causation or correlation. Exp Gerontol 2001, 36:1527-1537

9. Jensen LJ, Østergaard J, Flyvbjerg A: AGE-RAGE and AGE crosslink interaction: important players in the pathogenesis of diabetic kidney disease. Horm Metab Res 2005, 37(Suppl 1):26-34

10. Asif M, Egan J, Vasan S, Jyothirmayi GN, Masurekar MR, Lopez S, Williams C, Torres RL, Wagle D, Ulrich P, Cerami A, Brines M, Regan TJ: An advanced glycation endproduct cross-link breaker can reverse age-related increases in myocardial stiffness [Erratum appeared in Proc Natl Acad Sci USA 2000, 97:5679]. Proc Natl Acad Sci USA 2000, 97:2809-2813

11. Reiser KM: Influence of age and long-term dietary restriction on enzymatically mediated crosslinks and nonenzymatic glycation of collagen in mice. J Gerontol 1994, 49:B71-B79

12. López B, González A, Hermida N, Valencia F, de Teresa E, Díez J: Role of lysyl oxidase in myocardial fibrosis: from basic science to clinical aspects. Am J Physiol Heart Circ Physiol 2010, 299:H1-H9

13. Chang K, Uitto J, Rowold EA, Grant GA, Kilo C, Williamson JR: Increased collagen cross-linkages in experimental diabetes: reversal by beta-aminopropionitrile and D-penicillamine. Diabetes 1980, 29: 778-781

14. Bradshaw AD, Baicu CF, Rentz TJ, Van Laer AO, Bonnema DD, Zile MR: Age-dependent alterations in fibrillar collagen content and myocardial diastolic function: role of SPARC in post-synthetic procollagen processing. Am J Physiol Heart Circ Physiol 2009, 298: H614-H622

15. Khan R, Sheppard R: Fibrosis in heart disease: understanding the role of transforming growth factor-beta in cardiomyopathy, valvular disease and arrhythmia. Immunology 2006, 118:10-24

16. Wynn TA: Cellular and molecular mechanisms of fibrosis. J Pathol 2008, 214:199-210

17. Ikedo H, Tamaki K, Ueda S, Kato S, Fujii M, Ten Dijke P, Okuda S: Smad protein and TGF-beta signaling in vascular smooth muscle cells. Int J Mol Med 2003, 11:645-650

18. Brooks WW, Conrad CH: Myocardial fibrosis in transforming growth factor beta(1) heterozygous mice. J Mol Cell Cardiol 2000, 32:187-195

19. Rosin NL, Falkenham A, Sopel MJ, Lee TD, Légaré JF: Regulation and role of connective tissue growth factor in AngII-induced myocardial fibrosis. Am J Pathol 2013, 182:714-726

20. Rupérez M, Lorenzo O, Blanco-Colio LM, Esteban V, Egido J, RuizOrtega M: Connective tissue growth factor is a mediator of angiotensin II-induced fibrosis. Circulation 2003, 108:1499-1505

21. Wang X, McLennan SV, Allen TJ, Twigg SM: Regulation of proinflammatory and pro-fibrotic factors by CCN2/CTGF in H9c2 cardiomyocytes. J Cell Commun Signal 2010, 4:15-23

22. Sopel MJ, Rosin NL, Lee TD, Légaré JF: Myocardial fibrosis in response to angiotensin II is preceded by the recruitment of mesenchymal progenitor cells. Lab Invest 2010, 91:565-578

23. Underwood RA, Gibran NS, Muffley LA, Usui ML, Olerud JE: Color subtractive-computer-assisted image analysis for quantification of 
cutaneous nerves in a diabetic mouse model. J Histochem Cytochem 2001, 49:1285-1291

24. Ye J, Coulouris G, Zaretskaya I, Cutcutache I, Rozen S, Madden TL: Primer-BLAST: a tool to design target-specific primers for polymerase chain reaction. BMC Bioinformatics 2012, 13:134

25. Weber KT, Sun Y, Tyagi SC, Cleutjens JP: Collagen network of the myocardium: function, structural remodeling and regulatory mechanisms. J Mol Cell Cardiol 1994, 26:279-292

26. Koitabashi N, Arai M, Kogure S, Niwano K, Watanabe A, Aoki Y, Maeno T, Nishida T, Kubota S, Takigawa M, Kurabayashi M: Increased connective tissue growth factor relative to brain natriuretic peptide as a determinant of myocardial fibrosis. Hypertension 2007 , 49:1120-1127

27. Trojanowska M: Role of PDGF in fibrotic diseases and systemic sclerosis. Rheumatology (Oxford) 2008, 47(Suppl 5):v2-v4

28. Detillieux KA, Sheikh F, Kardami E, Cattini PA: Biological activities of fibroblast growth factor-2 in the adult myocardium. Cardiovasc Res 2003, 57:8-19

29. Lucero HA, Kagan HM: Lysyl oxidase: an oxidative enzyme and effector of cell function. Cellular and molecular life sciences: Cell Mol Life Sci 2006, 63:2304-2316

30. Fischer M, Baessler A, Hense HW, Hengstenberg C, Muscholl M, Holmer S, Döring A, Broeckel U, Riegger G, Schunkert H: Prevalence of left ventricular diastolic dysfunction in the community. Results from a Doppler echocardiographic-based survey of a population sample. Eur Heart J 2003, 24:320-328

31. Banerjee I, Fuseler JW, Price RL, Borg TK, Baudino TA: Determination of cell types and numbers during cardiac development in the neonatal and adult rat and mouse. Am J Physiol Heart Circ Physiol 2007, 293:H1883-H1891

32. Pinto AR, Paolicelli R, Salimova E, Gospocic J, Slonimsky E, Bilbao-Cortes D, Godwin JW, Rosenthal NA: An abundant tissue macrophage population in the adult murine heart with a distinct alternatively-activated macrophage profile. PLoS One 2012, 7:e36814

33. Courties G, Heidt T, Sebas M, Iwamoto Y, Jeon D, Truelove J, Tricot B, Wojtkiewicz G, Dutta P, Sager HB, Borodovsky A, Novobrantseva T, Klebanov B, Fitzgerald K, Anderson DG, Libby P, Swirski FK, Weissleder R, Nahrendorf M: In vivo silencing of the transcription factor IRF5 reprograms the macrophage phenotype and improves infarct healing. J Am Coll Cardiol 2014, 63:1556-1566

34. Heidt T, Courties G, Dutta P, Sager HB, Sebas M, Iwamoto Y, Sun Y, Da Silva N, Panizzi P, van der Lahn AM, Swirski FK, Weissleder R, Nahrendorf M: Differential contribution of monocytes to heart macrophages in steady-state and after myocardial infarction. Circ Res 2014, 115:284-295

35. Cieslik KA, Trial J, Entman ML: Defective myofibroblast formation from mesenchymal stem cells in the aging murine heart rescue by activation of the AMPK pathway. Am J Pathol 2011, 179:1792-1806

36. Boyle AJ, Shih H, Hwang J, Ye J, Lee B, Zhang Y, Kwon D, Jun K, Zheng D, Sievers R, Angeli F, Yeghiazarians Y, Lee R: Cardiomyopathy of aging in the mammalian heart is characterized by myocardial hypertrophy, fibrosis and a predisposition towards cardiomyocyte apoptosis and autophagy. Exp Gerontol 2011, 46:549-559

37. Flurkey K, Currer JM, Harrison DE. 2007. The mouse in aging research. In: The Mouse in Biomedical Research, 2nd Edition, Vol III, Normative Biology, Husbandry, and Models. Fox JG, Barthold SW, Davisson MT, Newcomer CE, Quimby FW, Smith AL. American College of Laboratory Animal Medicine (Elsevier), Burlington, MA. pp. 637-672

38. Domenighetti AA, Wang Q, Egger M, Richards SM, Pedrazzini T, Delbridge LM: Angiotensin II-mediated phenotypic cardiomyocyte remodeling leads to age-dependent cardiac dysfunction and failure. Hypertension 2005, 46:426-432

39. Bujak M, Kweon HJ, Chatila K, Li N, Taffet G, Frangogiannis NG: Aging-related defects are associated with adverse cardiac remodeling in a mouse model of reperfused myocardial infarction. J Am Coll Cardiol 2008, 51:1384-1392

40. Groban L, Lindsey S, Wang H, Lin MS, Kassik KA, Machado FS, Carter CS: Differential effects of late-life initiation of low-dose enalapril and losartan on diastolic function in senescent Fischer 344 $\times$ Brown Norway male rats. Age 2012, 34:831-843

41. Oxenham H, Sharpe N: Cardiovascular aging and heart failure. Eur J Heart Fail 2003, 5:427-434

42. Weis SM, Emery JL, Becker KD, McBride DJ Jr, Omens JH, McCulloch AD: Myocardial mechanics and collagen structure in the osteogenesis imperfecta murine (oim). Circ Res 2000, 87: $663-669$

43. Shivakumar K, Dostal DE, Boheler K, Baker KM, Lakatta EG: Differential response of cardiac fibroblasts from young adult and senescent rats to ANG II. Am J Physiol Heart Circ Physiol 2003, 284: H1454-H1459

44. Cai H, Yuan Z, Fei Q, Zhao J: Investigation of thrombospondin-1 and transforming growth factor-beta expression in the heart of aging mice. Exp Ther Med 2012, 3:433-436

45. Vater CA, Harris ED Jr, Siegel RC: Native cross-links in collagen fibrils induce resistance to human synovial collagenase. Biochem J 1979, 181:639-645

46. Tang SS, Trackman PC, Kagan HM: Reaction of aortic lysyl oxidase with beta-aminopropionitrile. J Biol Chem 1983, 258:4331-4338

47. Kato S, Spinale FG, Tanaka R, Johnson W, Cooper G 4th, Zile MR Inhibition of collagen cross-linking: effects on fibrillar collagen and ventricular diastolic function. Am J Physiol 1995, 269:H863-H868

48. Atsawasuwan P, Mochida Y, Katafuchi M, Kaku M, Fong KS, Csiszar K, Yamauchi M: Lysyl oxidase binds transforming growth factor-beta and regulates its signaling via amine oxidase activity. J Biol Chem 2008, 283:34229-34240

49. Pez F, Dayan F, Durivault J, Kaniewski B, Aimond G, Le Provost GS, Deux B, Clezardin P, Sommer P, Pouyssegur J, Reynaud C: The HIF-1-inducible lysyl oxidase activates HIF-1 via the Akt pathway in a positive regulation loop and synergizes with HIF-1 in promoting tumor cell growth. Cancer Res 2011, 71: $1647-1657$

50. Basu RK, Hubchak S, Hayashida T, Runyan CE, Schumacker PT, Schnaper HW: Interdependence of HIF-1alpha and TGF-beta/Smad3 signaling in normoxic and hypoxic renal epithelial cell collagen expression. Am J Physiol Renal Physiol 2011, 300:F898-F905

51. Voloshenyuk TG, Landesman ES, Khoutorova E, Hart AD, Gardner JD: Induction of cardiac fibroblast lysyl oxidase by TGFbeta1 requires PI3K/Akt, Smad3, and MAPK signaling. Cytokine 2011, 55:90-97

52. Kanematsu Y, Kanematsu M, Kurihara C, Tsou TL, Nuki Y, Liang EI, Makino H, Hashimoto T: Pharmacologically induced thoracic and abdominal aortic aneurysms in mice. Hypertension 2010, $55: 1267-1274$

53. Isoyama S, Ito N, Satoh K, Takishima T: Collagen deposition and the reversal of coronary reserve in cardiac hypertrophy. Hypertension 1992, 20:491-500

54. Rucker RB, Kosonen T, Clegg MS, Mitchell AE, Rucker BR, UriuHare JY, Keen CL: Copper, lysyl oxidase, and extracellular matrix protein cross-linking. Am J Clin Nutr 1998, 67(5 Suppl): 996S-1002S 